\title{
A Variação na Aquisição de Regras de Sândi Externo em Português Brasileiro*
}

\author{
(Variation in the Acquisiton of External Sandhi Rules \\ in Brazilian Portuguese)
}

\author{
Mariana Komatsu \& Raquel SAntos \\ (Universidade de São Paulo)
}

\begin{abstract}
This paper discusses the acquisition of external sandhi rules by one child learning Brazilian Portuguese. We show that these rules appear as soon as the child start putting two words together, but the rules are not uniform in the beginning of the process and are adult-like only around 3;6 years-old. We also show that the child use elision as a default strategy, that the prosodic properties of the rules are acquired before the segmental ones, and that the rules are not used for rhythmic optimization in the beginning of the acquisition process. Finally, our analysis provides support for Scarpa's analysis that prosodic acquisition proceeds from the higher to the lower levels.
\end{abstract}

KEY-WORDS: external sandhi rules; language acquisition; phonology, prosody.

RESUMO: Este artigo analisa a variação na aquisição do sândi externo por uma criança adquirindo português brasileiro. Nossos resultados mostram que essas regras aparecem tão logo a criança começa a combinar duas palavras, mas não são uniformes durante o período de aquisiz̧ão, estabilizando-se somente por volta de 3;6 anos. Mostramos que a criança usa a elisão como estratégia default, que as exigências segmentais das regras são adquiridas posteriormente às exigências prosódicas e que o uso dessas regras para implementação rítmica não ocorre nos períodos iníciais. Finalmente, nossa análise corrobora a proposta de Scarpa (1997) de que a aquisiz̧ão prosódica se inicia nos niveis mais altos da hierarquia.

PALAVRAs-CHAVE: regras de sandi externo; aquisição da linguagem; fonologia, prosódia.

* Agradecemos a Jairo M Nunes, às audiências do Second Lisbon Metting on Language Acquisition e Child Phonology Conference 2006, e a dois pareceristas anônimos a discussão deste texto. Todos os problemas remanescentes são falta unicamente nossa. A segunda autora agradece os auxilios a pesquisa de FAPESP (projeto 04/01806-0) e CNPq (processos 401024/2006-7 e 2006/311040).

D.E.L.T.A., 23:2, 2007 (223-244) 


\section{Introdução}

Nos últimos anos, as pesquisas sobre aquisição prosódica tem se intensificado, focalizando principalmente as línguas germânicas (cf. Demuth 1995, Demuth \& Fee 1996 para o inglês, Fikkert 1994 para o holandês). No entanto, a maioria dos estudos discute aspectos prosódicos que se estendem, no máximo, à palavra prosódica.

Não são muitos os trabalhos que discutem regras que se aplicam entre palavras. Stemberger (1989), Matthei (1989), Newton \& Wells (2002), embora tratem de processos fonológicos que ocorrem entre palavras (elisão, ressilabificação, assimilação de nasal, entre outros), discutem processos que alteram apenas seqüência segmental dos enunciados. Scarpa (1997, 2001) é a única que conhecemos que discute a aquisição de processos fonológicos que têm conseqüências para a estrutura rítmica. Segundo a autora, por volta de 2 anos, as crianças, adquirindo português brasileiro, utilizam regras de sândi externo. No entanto, essas regras são instáveis, variáveis, usadas para implementação rítmica.

Como a produção de enunciados com mais de duas palavras ocorre antes dos 2 anos, é possível que esses processos ocorram antes do período apontado por Scarpa. Tendo tal fato em mente, o objetivo deste artigo foi o de analisar um período maior no processo de aquisição de modo a responder duas questões:

i) quando e como as regras de sândi externo aparecem nas produções das crianças adquirindo português;

ii) como essas regras se relacionam com o desenvolvimento do sistema prosódico.

Este artigo está organizado da seguinte maneira: na seção 1 apresentamos as regras de sândi externo em português brasileiro e na seção 2 apresentamos os resultados de um estudo exploratório com adultos para checar se as exigências das regras apresentadas na seção 1 são obedecidas pelos falantes. Na seção 3 apresentamos os resultados dos dados observados nos dados infantis e na seção 4 discutimos esses resultados. Finalmente, a seção 5 traz as conclusões finais de nossa pesquisa. 


\section{Sândi externo em português brasileiro}

De acordo com Bisol (1992ab, 1996, 2003), para que as regras de sândi sejam aplicadas, as sílabas do contexto onde as regras serão aplicadas devem pertencer a um mesmo nível prosódico (frase fonológica ou entonacional). Segundo a autora, o contexto de aplicação das regras de sândi externo é:

a) degeminação: não ocorre se a segunda sílaba portar acento; pode ocorrer entre duas sílabas fracas (cf. exemplo (1)) ou entre uma sílaba forte e uma fraca (nesta ordem) (cf. exemplo (2)): ${ }^{1}$

1) $\mathrm{V}^{\mathrm{w}}+\mathrm{V}^{\mathrm{w}}$ ca'neta a'zul $\quad[\mathrm{ka} \text { 'neta'zuw }]_{\text {frase fonológica }}$

2) $V^{s}+V^{w}$ deci'di estu'dar [desi'dzistu'dar $]_{\text {frase fonologica }}$

b) elisão: a regra é bloqueada se a segunda sílaba é acentuada; a primeira vogal é /a/ e fraca (cf. exemplo (3)):

3) $/ a /{ }^{w}+V^{w}$ 'casa es'tranha ['kazis'trapa $]_{\text {frase fonológica }}$

c) ditongação: normalmente ocorre nas seqüências de duas vogais, em que uma das vogais é alta e não acentuada. (cf. exemplos (4)-(6)).

4) $\mathrm{V}^{\mathrm{s}}+\mathrm{V}^{\mathrm{w}}$ mai'ô es'curo [maj'ojs'kuru $]_{\text {frase fonológica }}$

5) $V^{\mathrm{w}}+\mathrm{V}^{\mathrm{w}}$ ele'fante afri'cano [ele'fãtjafri'kanu $]_{\text {frase fonológica }}$

6) $\mathrm{V}^{\mathrm{w}}+\mathrm{V}^{\mathrm{s}}$ 'falo 'árabe ['falwarabe $]_{\text {frase entoacional }}$

Saliente-se que há contextos em que é possível tanto a ditongação quanto a elisão, e que a ditongação abrange mais contextos de aplicação, tanto por não restringir a qualidade da primeira vogal, quanto por permitir que o processo ocorra quando uma vogal porta acento.

Os contextos em que ditongação e elisão são possíveis, segundo a análise de Bisol, são contextos formados por $/ \mathrm{a} /{ }^{\mathrm{w}}+\mathrm{V}^{\mathrm{w}}$ em que a segunda vogal é alta. Bisol (1992ab, 1996, 2003), analisando os dados do projeto

1 Como notação, usamos $\mathrm{V}$ para indicar a vogal; em super-escrito, $w$ para sílaba fraca e $s$ para sílaba forte; em sub-escrito, os traços das vogais envolvidas. A segunda coluna indica o contexto, em negrito, com a marcação do acento. A segunda coluna indica a produção. 
NURC, para as cinco capitais, afirma que há a preferência pela ditongação. Nogueira $(2006,2007)$ aponta, no entanto, que em São Paulo, nos contextos em que a primeira vogal é /a/ w elisão ou ditongação são possíveis, a elisão é aplicada em $94 \%$ das vezes, enquanto que a ditongação o é em apenas $4,16 \%$.

Apesar de uma preferência pela elisão em SP, os dados sobre a distribuição da elisão são compatíveis com os resultados de Bisol de que a elisão com /a/ é mais geral do que a elisão com outras vogais em primeira posição: a elisão com [a] ocorre em $94 \%$ dos casos, enquanto a elisão com [u] ocorre em $62 \%$. Finalmente, Nogueira também aponta que é possível a elisão com [i], mas em apenas 15\% dos casos (para análise de outros dialetos, cf. também Brescancini 2005, Veloso 2003).

Tenani (2002) chama a atenção para a opcionalidade das regras de sândi externo. Segundo a autora, essas regras não são restritas a nenhum domínio prosódico, isto é, podem ocorrer mesmo entre sentenças (Us), mas são obrigatórias no domínio da frase fonológica.

\section{Produção e Julgamento de gramaticalidade na fala adulta}

Levando em conta as análises de sândi externo expostas na seção 1, Komatsu (2003) analisou a produção e o julgamento de gramaticalidade na aplicação de regras de sândi externo por 5 falantes do português brasileiro. Para o teste de produção, a autora pediu que os sujeitos da pesquisa lessem as sentenças silenciosamente e depois as produzissem de forma mais natural possível. As sentenças que foram produzidas com velocidade muito rápida ou muito lenta foram descartadas e somente foram consideradas as sentenças com velocidade de fala considerada normal. ${ }^{2}$ Ao invés de um teste de percepção, em que os sujeitos apenas mostrariam ser bom ouvintes, Komatsu aplicou um teste de julgamento, em que os sujeitos ouviam sentenças em que eram aplicadas regras de sândi externo e diziam se a sentença era boa ou não em português.

\footnotetext{
2 Sabemos que a definição da velocidade de fala como 'rápida, lenta ou normal' é um pouco impressionística, dependendo muito do julgamento do experimentador. No entando, não era objetivo desta pesquisa fazer uma análise acústica que considerasse a quantidade de sílabas pronunciadas pelo falante em um determinado recorte de tempo. De modo a minimizar a questão, o julgamento da velocidade de fala dos sujeitos foi feita por um mesmo pesquisador, para garantir a uniformidade dos julgamentos.
} 
Foram 190 sentenças, controladas nos seguintes fatores: o domínio prosódico (o contexto em todas as sentenças era dentro de uma mesma frase fonológica), a proeminência das sílabas (forte vs fraca), o tipo de vogal envolvida no contexto (altas - /i,o,u,e/ vs baixas /a, $\varepsilon, \circ, /$ ), e coincidência acentual (acento de palavra e entoacional coincidem vs acento de palavra e entoacional não coincidem). Seus resultados encontram-se nas tabelas (1) e (2), abaixo (os números absolutos estão entre parênteses):

Tabela 1: Acento de palavra e acento entoacional não coincidem.

\begin{tabular}{|c|c|c|c|c|c|c|c|c|c|c|}
\hline \multirow{3}{*}{ Contexto } & \multicolumn{3}{|c|}{ Degeminação } & \multicolumn{3}{|c|}{ Elisão } & \multicolumn{3}{|c|}{ Ditongação } & \multirow[t]{3}{*}{ Total } \\
\hline & \multirow[t]{2}{*}{ Produção } & \multicolumn{2}{|c|}{$\begin{array}{l}\text { Julgamento de } \\
\text { gramaticalidade }\end{array}$} & \multirow[t]{2}{*}{ Produção } & \multicolumn{2}{|c|}{$\begin{array}{l}\text { Julgamento de } \\
\text { gramaticalidade }\end{array}$} & \multirow[t]{2}{*}{ Produção } & \multicolumn{2}{|c|}{$\begin{array}{l}\text { Julgamento de } \\
\text { gramaticalidade }\end{array}$} & \\
\hline & & Aceitação & Rejeição & & Aceitação & Rejeição & & Aceitação & Rejeição & \\
\hline$s b+s b$ & $\begin{array}{l}2.22 \% \\
(1)\end{array}$ & $6.66 \%(3)$ & $\begin{array}{l}91.11 \% \\
(41)\end{array}$ & $0 \%$ & $0 \%$ & $\begin{array}{l}100 \% \\
(45)\end{array}$ & $0 \%$ & $\begin{array}{l}4.44 \% \\
(2) \\
\end{array}$ & $\begin{array}{l}95.5 \% \\
(43)\end{array}$ & $\begin{array}{l}100 \% \\
(45)\end{array}$ \\
\hline$w b+s b$ & $0 \%$ & $26.6 \%(4)$ & $\begin{array}{l}73.3 \% \\
(11)\end{array}$ & $\begin{array}{l}6.66 \% \\
(1)\end{array}$ & $\begin{array}{l}13.33 \% \\
(2)\end{array}$ & $\begin{array}{l}80 \% \\
(12)\end{array}$ & $0 \%$ & $0 \%$ & $\begin{array}{l}100 \% \\
(15)\end{array}$ & $\begin{array}{l}100 \% \\
(15)\end{array}$ \\
\hline$s b+w b$ & \begin{tabular}{|l}
$26.65 \%$ \\
$(4)$ \\
\end{tabular} & $6.66 \%(1)$ & $\begin{array}{l}66.66 \% \\
(10) \\
\end{array}$ & $0 \%$ & $0 \%$ & $\begin{array}{l}100 \% \\
(15) \\
\end{array}$ & $20 \%(3)$ & $\begin{array}{l}26.66 \% \\
(4) \\
\end{array}$ & $\begin{array}{l}53.33 \% \\
(8) \\
\end{array}$ & $\begin{array}{l}100 \% \\
(15) \\
\end{array}$ \\
\hline$w b+w b$ & $\begin{array}{l}100 \% \\
(5)\end{array}$ & $0 \%$ & $0 \%$ & $0 \%$ & $0 \%$ & $\begin{array}{l}100 \% \\
(5)\end{array}$ & $0 \%$ & $0 \%$ & $\begin{array}{l}100 \% \\
(5)\end{array}$ & $\begin{array}{l}100 \% \\
(5)\end{array}$ \\
\hline $\mathrm{sb}+\mathrm{sa}$ & $0 \%$ & $0 \%$ & $\begin{array}{l}100 \% \\
(60)\end{array}$ & $0 \%$ & $0 \%$ & $\begin{array}{l}100 \% \\
(60)\end{array}$ & $\begin{array}{l}13.33 \% \\
(8)\end{array}$ & $\begin{array}{l}18.33 \% \\
(11) \\
\end{array}$ & $\begin{array}{l}68.33 \% \\
(41) \\
\end{array}$ & $\begin{array}{l}100 \% \\
(60)\end{array}$ \\
\hline $\mathrm{wb}+\mathrm{sa}$ & $0 \%$ & $0 \%$ & $\begin{array}{l}100 \% \\
(20)\end{array}$ & $30 \%(6)$ & $15 \%(3)$ & $\begin{array}{l}55 \% \\
(11) \\
\end{array}$ & $0 \%$ & $0 \%$ & \begin{tabular}{|l|}
$100 \%$ \\
$(20)$
\end{tabular} & $\begin{array}{l}100 \% \\
(20) \\
\end{array}$ \\
\hline $\mathrm{sb}+\mathrm{wa}$ & $0 \%$ & $0 \%$ & $\begin{array}{l}100 \% \\
(60)\end{array}$ & $0 \%$ & $0 \%$ & $\begin{array}{l}100 \% \\
(60)\end{array}$ & $\begin{array}{l}35 \% \\
(21)\end{array}$ & $\begin{array}{l}28.33 \% \\
(17)\end{array}$ & \begin{tabular}{|l}
$36.66 \%$ \\
$(22)$
\end{tabular} & $\begin{array}{l}100 \% \\
(60)\end{array}$ \\
\hline$w b+w a$ & $0 \%$ & $0 \%$ & $\begin{array}{l}100 \% \\
(20)\end{array}$ & $\begin{array}{l}60 \% \\
(12) \\
\end{array}$ & $20 \%(4)$ & $20 \%(4)$ & $5 \%(1)$ & $15 \%(3)$ & $\begin{array}{l}80 \% \\
(16)\end{array}$ & $\begin{array}{l}100 \% \\
(20)\end{array}$ \\
\hline$s a+s b$ & $0 \%$ & $0 \%$ & $\begin{array}{l}100 \% \\
(60)\end{array}$ & $0 \%$ & $0 \%$ & $\begin{array}{l}100 \% \\
(60)\end{array}$ & $\begin{array}{l}16.66 \% \\
(10)\end{array}$ & $10 \%(6)$ & \begin{tabular}{|l}
$73.33 \%$ \\
$(44)$
\end{tabular} & $\begin{array}{l}100 \% \\
(60)\end{array}$ \\
\hline $\mathrm{wa}+\mathrm{sb}$ & $0 \%$ & $0 \%$ & $\begin{array}{l}100 \% \\
(30)\end{array}$ & $0 \%$ & $0 \%$ & $\begin{array}{l}100 \% \\
(30)\end{array}$ & $\begin{array}{l}36.66 \% \\
(11)\end{array}$ & $\begin{array}{l}26.66 \% \\
(8) \\
\end{array}$ & $\begin{array}{l}36.66 \% \\
(11) \\
\end{array}$ & $\begin{array}{l}100 \% \\
(30)\end{array}$ \\
\hline$w a+w b$ & $0 \%$ & $0 \%$ & $\begin{array}{l}100 \% \\
(10)\end{array}$ & $0 \%$ & $0 \%$ & $\begin{array}{l}100 \% \\
(10)\end{array}$ & $70 \%(7)$ & $10 \%(1)$ & $20 \%(2)$ & $\begin{array}{l}100 \% \\
(10)\end{array}$ \\
\hline $\mathrm{sa}+\mathrm{wb}$ & $0 \%$ & $0 \%$ & $\begin{array}{l}100 \% \\
(20) \\
\end{array}$ & $0 \%$ & $0 \%$ & $\begin{array}{l}100 \% \\
(20)\end{array}$ & \begin{tabular}{|l}
$50 \%$ \\
$(10)$ \\
\end{tabular} & $10 \%(2)$ & $40 \%(8)$ & $\begin{array}{l}100 \% \\
(20)\end{array}$ \\
\hline $\mathrm{sa}+\mathrm{sb}$ & $0 \%$ & $15 \%(12)$ & $\begin{array}{l}85 \% \\
(68)\end{array}$ & $0 \%$ & $0 \%$ & $\begin{array}{l}100 \% \\
(80)\end{array}$ & $10 \%(8)$ & $\begin{array}{l}21.25 \% \\
(17)\end{array}$ & $\begin{array}{l}68.75 \% \\
(55)\end{array}$ & $\begin{array}{l}100 \% \\
(80)\end{array}$ \\
\hline $\mathrm{wa}+\mathrm{sa}$ & $0 \%$ & $0 \%$ & $\begin{array}{l}100 \% \\
(40)\end{array}$ & $7.5 \%(3)$ & $7.5 \%(3)$ & $\begin{array}{l}85 \% \\
(34)\end{array}$ & $\begin{array}{l}47.5 \% \\
(19)\end{array}$ & $15 \%(6)$ & $\begin{array}{l}37.5 \% \\
(15)\end{array}$ & $\begin{array}{l}100 \% \\
(40)\end{array}$ \\
\hline sav + wa & $5 \%(4)$ & $6.25 \%(5)$ & $\begin{array}{l}88.75 \% \\
(71)\end{array}$ & $5 \%(4)$ & $\begin{array}{l}1.25 \% \\
(1)\end{array}$ & $\begin{array}{l}\begin{array}{l}93.75 \% \\
(75)\end{array} \\
\end{array}$ & $\begin{array}{l}26.25 \% \\
(21)\end{array}$ & $15 \%(12)$ & \begin{tabular}{|l}
$58.75 \%$ \\
$(47)$
\end{tabular} & $\begin{array}{l}100 \% \\
(80)\end{array}$ \\
\hline wa + wa & $\begin{array}{l}25 \% \\
(10)\end{array}$ & $0 \%$ & $\begin{array}{l}75 \% \\
(30) \\
\end{array}$ & $\begin{array}{l}12.5 \% \\
(5)\end{array}$ & $\begin{array}{l}12.5 \% \\
(5)\end{array}$ & \begin{tabular}{|l}
$75 \%$ \\
$(30)$ \\
\end{tabular} & $\begin{array}{l}42.5 \% \\
(17) \\
\end{array}$ & $15 \%(6)$ & \begin{tabular}{|l|}
$42.5 \%$ \\
$(17)$ \\
\end{tabular} & $\begin{array}{l}100 \% \\
(40)\end{array}$ \\
\hline
\end{tabular}

$\mathrm{sb}=$ vogal baixa, sílaba acentuada $\mathrm{wb}=$ vogal baixa, sílaba átona sa $=$ vogal alta, sílaba acentuada wa $=$ vogal alta, sílaba átona 
Tabela 2: Acento de palavra e acento entoacional coincidem.

\begin{tabular}{|c|c|c|c|c|c|c|c|c|c|c|}
\hline \multirow{3}{*}{ Contexto } & \multicolumn{3}{|c|}{ Degeminação } & \multicolumn{3}{|c|}{ Elisão } & \multicolumn{3}{|c|}{ Ditongação } & \multirow{3}{*}{ Total } \\
\hline & \multirow[t]{2}{*}{ Produção } & \multicolumn{2}{|c|}{$\begin{array}{l}\text { Julgamento de } \\
\text { gramaticalidade }\end{array}$} & \multirow[t]{2}{*}{ Produção } & \multicolumn{2}{|c|}{$\begin{array}{l}\text { Julgamento de } \\
\text { gramaticalidade }\end{array}$} & \multirow[t]{2}{*}{ Produção } & \multicolumn{2}{|c|}{$\begin{array}{l}\text { Julgamento de } \\
\text { gramaticalidade }\end{array}$} & \\
\hline & & Aceitação & Rejeição & & Aceitação & Rejeição & & Aceitação & Rejeição & \\
\hline$s b+s b$ & $0 \%$ & $0 \%$ & $\begin{array}{l}100 \% \\
(45)\end{array}$ & $0 \%$ & $0 \%$ & $\begin{array}{l}100 \% \\
(45)\end{array}$ & $0 \%$ & $0 \%$ & $\begin{array}{l}100 \% \\
(45)\end{array}$ & $\begin{array}{l}100 \% \\
(45)\end{array}$ \\
\hline$w b+s b$ & $0 \%$ & $0 \%$ & $\begin{array}{l}100 \% \\
(15)\end{array}$ & $0 \%$ & $0 \%$ & $\begin{array}{l}100 \% \\
(15)\end{array}$ & $0 \%$ & $0 \%$ & $\begin{array}{l}100 \% \\
(15)\end{array}$ & $\begin{array}{l}100 \% \\
(15)\end{array}$ \\
\hline$s b+s a$ & $0 \%$ & $0 \%$ & $\begin{array}{l}100 \% \\
(60)\end{array}$ & $0 \%$ & $0 \%$ & $\begin{array}{l}100 \% \\
(60)\end{array}$ & $0 \%$ & $0 \%$ & $\begin{array}{l}100 \% \\
(60)\end{array}$ & $\begin{array}{l}100 \% \\
(60)\end{array}$ \\
\hline $\mathrm{wb}+\mathrm{sa}$ & $0 \%$ & $0 \%$ & $\begin{array}{l}100 \% \\
(20)\end{array}$ & $0 \%$ & $0 \%$ & $\begin{array}{l}100 \% \\
(20)\end{array}$ & $0 \%$ & $0 \%$ & $\begin{array}{l}100 \% \\
(20)\end{array}$ & $\begin{array}{l}100 \% \\
(20)\end{array}$ \\
\hline $\mathrm{sa}+\mathrm{sb}$ & $0 \%$ & $0 \%$ & $\begin{array}{l}100 \% \\
(60)\end{array}$ & $0 \%$ & $0 \%$ & $\begin{array}{l}100 \% \\
(60)\end{array}$ & $5 \%(3)$ & $\begin{array}{l}1.66 \% \\
(1)\end{array}$ & $\begin{array}{l}93.33 \% \\
(56) \\
\end{array}$ & $\begin{array}{l}100 \% \\
(60)\end{array}$ \\
\hline$w a+s b$ & $0 \%$ & $0 \%$ & $\begin{array}{l}100 \% \\
(30)\end{array}$ & $0 \%$ & $0 \%$ & $\begin{array}{l}100 \% \\
(30)\end{array}$ & $20 \%(6)$ & $\begin{array}{l}23.33 \% \\
(7)\end{array}$ & $\begin{array}{l}56.66 \% \\
(17)\end{array}$ & $\begin{array}{l}100 \% \\
(30)\end{array}$ \\
\hline $\mathrm{sa}+\mathrm{sa}$ & $0 \%$ & $2.5 \%(2)$ & $\begin{array}{l}97.5 \% \\
(78) \\
\end{array}$ & $0 \%$ & $0 \%$ & $\begin{array}{l}100 \% \\
(80)\end{array}$ & $0 \%$ & $\begin{array}{l}6.25 \% \\
(5) \\
\end{array}$ & $\begin{array}{l}93.75 \% \\
(75)\end{array}$ & $\begin{array}{l}100 \% \\
(80)\end{array}$ \\
\hline $\mathrm{wa}+\mathrm{sa}$ & $0 \%$ & $0 \%$ & $\begin{array}{l}100 \% \\
(40)\end{array}$ & $0 \%$ & $0 \%$ & $\begin{array}{l}100 \% \\
(40)\end{array}$ & $\begin{array}{l}22.5 \% \\
(9) \\
\end{array}$ & $7.5 \%(3)$ & $\begin{array}{l}70 \% \\
(28)\end{array}$ & $\begin{array}{l}100 \% \\
(40)\end{array}$ \\
\hline
\end{tabular}

$\mathrm{sb}=$ vogal baixa, sílaba acentuada

sa $=$ vogal alta, sílaba acentuada

$\mathrm{wb}=$ vogal baixa, sílaba átona

wa $=$ vogal alta, sílaba átona

Como exemplo de não-coincidência entre acento de palavra e acento entonacional, cf. (7), e como exemplo de coincidência entre o acento de palavra e acento entonacional, cf. (8):

7) [[Sobrou $\left.[\text { esse ovo }]_{\text {frase fonológica }}[\text { na geladeira }]_{\text {frase fonológica }}\right]_{\text {frase entonational }}$ wav + sav

8) [[Sobrou $\left.[\text { [esse ovo }]_{\text {frase fonológica }}\right]_{\text {frase entonational }}$ wav + sav

Em (8), o acento em ['ovo] é acento da frase entoacional e, ao mesmo tempo, acento da frase entonacional. O mesmo não ocorre em (7). Neste caso, embora o acento em ['ovo] seja acento de palavra e a proeminência da frase fonológica, a proeminência entoacional encontra-se em [gela'dejra].

Como é possível observar na tabela (1), quando os acentos de palavra e entoacional não coincidem, a produção e aceitação dos processos de sândi externo dependem exclusivamente dos traços das vogais e da proeminência (acento de palavra) da segunda sílaba. Os casos de completa rejeição são aqueles em que ou a altura da vogal ou a proeminência da segunda sílaba são excluídos das regras, conforme apontado por Bisol. Mas os resul- 
tados também apontam que os sujeitos aceitam a elisão quando a primeira vogal é diferente de /a/ (cf. (9)):

9) Eu quero este livro [ew 'ke.res.te.'li.vru] wa + sa

Estes resultados estão de acordo com a proposta de Santos (prep) de que a regra de elisão, na realidade, se aplica quando a primeira vogal é [+ posterior]. A autora argumenta que a vogal /a/ em português brasileiro é mais central e analisada como vogal $[+$ posterior $]$. Assim, a regra de elisão se aplica nos casos em que a primeria vogal é [+ posterior], isto é, para o conjunto de vogais /a,o,o,u/. Como a vogal /っ/ só ocorre em sílabas tônicas e a regra de elisão exige que a primeira vogal seja átona, as vogais sujeitas a elisão são /a,o,u/.

Podemos observar na tabela (2) que, quando há coincidência entre o acento de palavra e o acento entonacional, os adultos tendem a evitar ou rejeitar a aplicação das regras. No entanto, há uma diferença de comportamento no que se refere ao tipo de regra utilizada; por um lado, as regras de elisão e degeminação são totalmente bloqueadas quando os acentos de palavra e entoacional coincidem. Por outro lado, a ditongação pode ocorrer (mesmo que marginalmente) nestes contextos. A questão que se coloca é porque isso ocorre. Quando observamos os contextos desses casos (sav + sbv, wav + sbv, sav + sav, wav + sav), todos eles têm uma variável em comum: a primeira vogal envolvida tem o traço [ + alto]. Segundo Bisol, para a ditongação ocorrer uma das vogais deve ter o traço $[+$ alto $]$; não influenciando a posição dessa vogal no contexto (primeira ou segunda sílaba). $\mathrm{O}$ que os sujeitos produzem e aceitam, no entanto, não se conforma exatamente com a regra. Os sujeitos violam a coincidência acentual que bloqueia a regra nos casos em que a primeira vogal é $[+$ alta $]$, mas nunca o fazem se a primeira vogal é $[+$ baixa $]$.

\section{Aquisição da Linguagem}

A partir dos resultados com os experimentos de produção e julgamento de gramaticalidade para sentenças com aplicação de regras de sândi, analisamos a aquisição dessas regras por crianças adquirindo o português brasileiro, a partir das afirmações de Scarpa (1997). 


\subsection{Metodologia}

Os dados analisados para este estudo são de uma criança - R. - entre 1;4 anos e 3;6 anos, gravada semanalmente em áudio. Esses dados fazem parte do Projeto de Aquisição da Linguagem do Instituto de Estudos da Linguagem - Unicamp (cf. Lemos 1995). Os dados foram transcritos por pesquisadores do projeto em questão e foram checados pelas duas autoras deste artigo. R. foi uma das crianças que tiveram seus dados analisados por Scarpa $(1997,2001)$ e a escolha por esta criança foi intencional, pois nosso objetivo é observar, a partir da análise de Scarpa, se a aquisição das regras de sândi externo sofreu alguma modificação no percuso do desenvolvimento prosódico da criança.

Foram selecionadas 6 sessões, aos 1;4, 1;8, 1;11, 2;6, 3;0 e 3;6 anos. A decisão de iniciar a seleção aos $1 ; 4$ se deu de modo a garantir que a criança já tivesse adquirido a estrutura silábica necessária para ditongação.

De cada sessão, selecionamos todas as produções que tivessem mais de uma palavra e que uma das palavras (que não fosse a primeira palavra do enunciado) fosse iniciada por vogal, criando, portanto, um possível contexto mínimo para aplicação de regras de sândi externo. Chamamos a atenção de que bastava que houvesse duas palavras no mesmo enunciado e a segunda palavra iniciasse por vogal, independentemente de o contexto não ser, necessariamente, o contexto para aplicação de regras de sândi externo (por exemplo, com uma combinação de vogais diferentes, ou com proeminências que bloqueariam as regras). Estas sentenças foram classificadas de acordo com o processo de sândi produzido (ou bloqueado) e a optimização rítmica que a regra de sândi gerava.

\subsection{Aquisição da Estrutura silábica}

Como dito em 3.1, uma vez que uma das regras de sândi é a ditongação, que preenche uma estrutura CVV, é necessário saber quando as crianças começam a produzir esse tipo de estrutura silábica.

De acordo com Santos (1998) e Mezzomo \& Menezes (2001), a seqüência de desenvolvimento da estrutura silábica no português brasileiro é:

10) V, CV $>>C V C, \mathrm{CVV}_{\text {glide }}>>\mathrm{CV}_{\text {glide }} \mathrm{V}, \mathrm{CVCC}$ 
Santos (1998) mostra que os ditongos decrescentes aparecem para R. por volta de $1 ; 5$ anos e os ditongos crescentes por volta de 2;0, como ilustrado na tabela (3):

Tabela 3: faixa etária de R. para aquisição das estruturas silábicas

\begin{tabular}{|l|l|l|l|l|}
\hline & \multicolumn{1}{|c|}{ CVC } & \multicolumn{3}{c|}{ CVV } \\
\hline & Inicial e medial & \multicolumn{2}{|c|}{ Ditongos decrescentes } & Ditongos crescentes \\
\hline & & pesados & Leves & \\
\hline Idade & $1 ; 11$ & $1 ; 6$ & $1 ; 5$ & $2 ; 0$ \\
\hline
\end{tabular}

A distinção entre ditongos pesados e leves segue Bisol (1989). De acordo com a autora, ditongos pesados preenchem duas posições no núcleo e não podem ser reduzidos (cf. (11)). Ditongos leves, por outro lado, preenchem apenas uma posição no núcleo e podem ser reduzidos (cf. (12)):
11) leite
['lej.tsi $] \sim *\left[{ }^{\prime}\right.$ le.tSi $]$
12) peixe
['pej.Si] $\sim$ ['pej.Si]

\subsection{Regras de sândi externo}

Nesta seção, discutimos como R. aplica as regras de sândi externo. Dividimos as 6 sessões analisadas em 4 grupos que, como apontaremos, refletem 4 momentos no desenvolvimento prosódico de R. Estes momentos (fases) não refletem nenhuma marcação paramétrica, mas mostram como as regras de sândi são utilizadas de maneira diferente pela criança.

\section{a) Fase I:}

Como dito na seção anterior, R. tinha 1;4 anos na primeira sessão analisada. Nesta idade, todas as suas produções têm a extensão de uma palavra, e, portanto, não há contexto favorável para a aplicação de sândi externo. 


\section{b) Fase II:}

A sessão em que R. tinha 1;8 anos apresenta sentenças com mais de uma palavra, embora sejam normalmente curtas (duas palavras). Aos 2;6 anos, R. produz sentenças mais longas, com 4 a 5 palavras, o que cria mais contextos para aplicação de sândi, principalmente evitando a coincidência do acento entoacional com o acento de palavra da segunda sílaba de contexto de sândi. Apesar desta importante diferença, nesses três momentos $(1 ; 8,1 ; 11$ e $2 ; 6$ anos) as produções de $\mathrm{R}$. têm as mesmas características no que se refere à aplicação de sândi externo, a saber, a) aplicação instável das regras de sândi; b) as regras aplicadas são diferentes das usadas pelos adultos; c) as regras não são usadas para otimização rítmica das sentenças; d) o acento bloqueia as regras de sândi.

Os exemplos abaixo ilustram a sentença a ser produzida (à esquerda), possíveis produções na fala do adulto (no centro), e a produção de R. (à direita): ${ }^{3}$

$1 ; 8.25$ anos:

13) tira outra ['ti.ra.'o.tra] ['ti.ra.'o.tra]

14) nanar aqui [na.'na.ra.'ki] [na.'na.'ki]

15) tira aqui ['ti.ra.'ki] ['ti.ra.a.'ki]

O que pode ser observado nestes exemplos é que em (13) o acento bloqueia a ditongação. Uma vez que o acento primário da segunda palavra também carrega o acento entonacional, duas análises são possíveis: ou que o acento primário bloqueia a ditongação, ou que o acento entoacional bloqueia a ditongação.

Em (14) e (15), a segunda vogal é fraca. Como pode ser visto, em (14) R. aplica degeminação, enquanto em (15) não aplica nenhuma regra. Tal fato ilustra a instabilidade da aplicação das regras. O exemplo (14) também mostra que a aplicação da regra gera uma seqüência de encontro acentual, não otimizando ritmicamente a produção da criança.

3 Exceto quando a sentença for muito longa. Neste caso, identificaremos a produção do adulto e da criança como no dado (24). indica mais de uma opção na produção. 


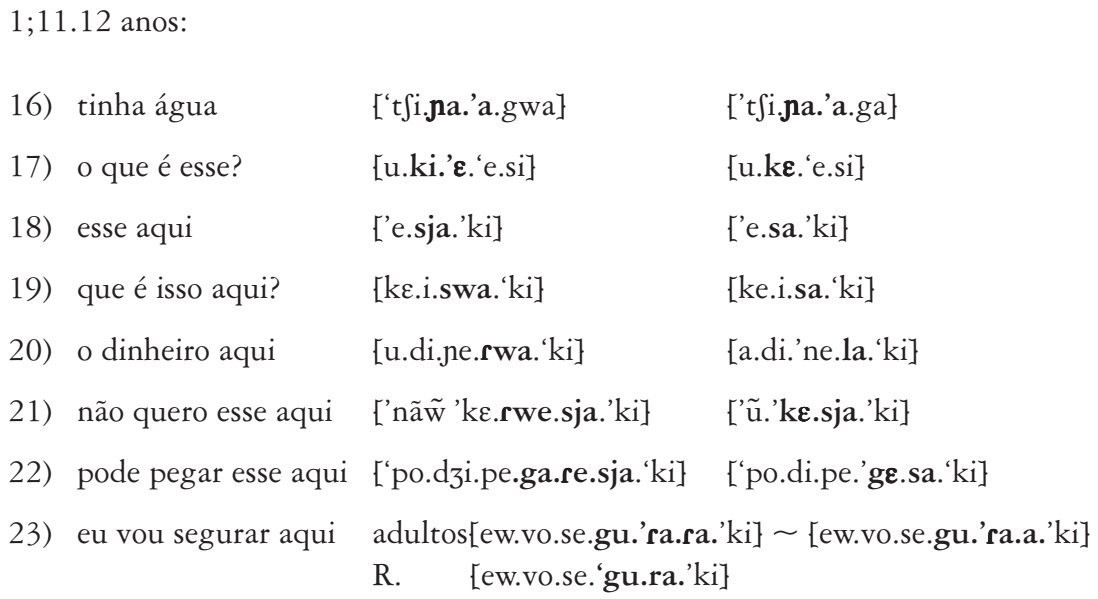

Aos $1 ; 11, \mathrm{R}$. continua obedecendo à exigência do bloqueio de regra quando há acento na segunda sílaba, como é possível observar em (16) e (17). Em (17), há dois possíveis contextos mínimos para aplicação de regra: 'que é' e 'é esse'. Em ambos os contextos, a segunda sílaba recebe acento de palavra, mas no segundo contexto, além do acento de palavra, a segunda sílaba porta também o acento entonacional. R. não aplica nenhuma regra no segundo contexto, mas aplica elisão no primeiro contexto.

Em (18)-(19), R. usa elisão quando os adultos usariam ditongação. Ela, além disso, apaga a primeira vogal e mantém somente a vogal [+ baixa], a segunda do contexto. Embora pareça haver uma preferência por elisão, se comparamos (18)-(20) com (21), podemos observar que a aplicação da regra ainda é instável. Em (21), adultos ditongariam no primeiro contexto ('quero esse'), enquanto R. apaga toda a sílaba. Em (22) e (23), R. aplica elisão e degeminação, respectivamente, quando adultos não aplicariam nenhuma regra. No caso de (22), a aplicação da regra gera uma seqüência mais eurritmica, mas em (23), a seqüência resultante cria um encontro acentual [segu'ra'ki] que R. evita movendo o acento para a sílaba anterior.

\section{2;6.12 anos:}

24) cadê ele?

[ka.'de.'e.li

[ka.'de.'e.li]

25) depois é este.

[de.'pojs.'昚.'es.tfI]

[de.pojs.e.'es.tfI]

26) eu vou desmanchar ele. [ew.'vo.dzis.mã.'Ja.'re.lı] [ew.'vo.dzis.mã.'Ja.'e.li] 
27) só isso. [so.'i.su] [so.'i.su]

28) cadê o trenzinho? [ka.'de.u.trẽj.'zi.nu] [ka.'dew.trẽj.'zi.nu] [ka.'dew.trẽj.'zi.nu]

29) este aqui [es.tjja.'kI]

[es.tsja.'kI]

30) esse é pequeno e eu pus aqui.

adulto ['e.sje.pe ke.nuj.ew.'pujs.a 'ki]

R. [e.'s $\boldsymbol{\varepsilon}$.pe ke.nuj.ew.'pujs.a'ki]

31) aquele que foi pra unicamp. adulto [a.'ke.li.ke.'foj.praw.ni.'kã.pi] [a.'ke.li.ke.'foj.pru.ni.'kã.pi]

R. [a.'ke.lı.ke.'foj.pa.ni.'kã.po]

32) esse pequeno ficou aqui. ['e.se.pe.'ke.nu.fi.'ks.a.'kI] ['e.se.pe.'ke.nu.fi.'ko.'kI]

O acento continua a bloquear as regras de sândi, como é possível observar em (24)-(27). Em (28)-(29), R. aplica a mesma regra que os adultos, ditongação. Por outro lado, (30)-(31) são exemplos de estratégias diferentes das usadas pelos adultos. Em (31), deveria haver uma pausa entre 'pequeno' e 'e', e ocorrer ditongação entre 'esse' e 'é'. R., no entanto, ditonga no primeiro contexto e usa elisão no segundo. Em (31), R parece aplicar elisão, mas se esse fosse o caso, ela deveria elidir a vogal /a/. Uma possível análise para o fato é que $R$. escolhe manter a vogal $[+$ baixa $]$ como estratégia default. No entanto, (32) mostra que não é este o caso, uma vez que ela apaga o /a/. Em (32) é possível também observar que R. não usa a regra de sândi para implementação rítmica. Se fosse esse o caso, ela não aplicaria a regra e a seqüência resultante seria eurrítmica (forte, fraca, forte ['ko.a.'ki]. No entanto, ela aplica a regra e cria um encontro acentual.

Nos examplos (30)-(31), podemos observar que o acento que bloqueia a regra de sândi é o acento entonacional. Em (30) R. usa elisão na seqüência 'esse é', onde adultos aplicariam ditongação. A aplicação das duas regras (elisão e ditongação) são possíveis, mesmo que 'é' receba acento de palavra, pois não recebe acento entonacional. $\mathrm{O}$ mesmo pode ser dito de (31), onde adultos ditongariam ou usariam elisão. No contexto, /u/ em 'unicamp' porta acento secundário, o que não bloqueia as regras de sândi. R. aplica elisão (mas "erra" no segmento a ser apagado).

\section{c) Fase III:}

Aos 3;0 anos, o uso das regras de sândi ainda é instável. No entanto, diferentemente das fases anteriores, as regras são sempre utilizadas para a otimização rítmica. 
3;0.15 anos:

33) sabe quem chama esse? ['sa.be.kẽ.fa.ma.'e.sı] ['sa.be.kẽ.fa.ma.'e.si]

34) só arroz ['so.a.'xo.js] ['so.a.'xo.js]

35) vou comer tudo a comida da Daniela. adulto [vo.ko.me.tu.dwa.ko.mi.da.da.da.ni.e.la] [vo.ko.me.tu.da.ko.mi.da.da.da.ni.e.la]

R. [vo.'ko. me.tu.dwa.ko.'mi.da.da.da.ni.'e.la]

36) faz uma máscara que parece uma batata. adulto ['faz.'u.ma.'mas.ka.ra.kI.pa.'re.sju.ma.ba.'ta.ta] R. [faz.'u.ma.'mas.ka.ra.ki.pa.'re.sı.'u.ma.ba.'ta.ta]

37) aquele que põe canudinho assim. adulto [a.'ke.lı.kI.'põj.ka.nu.'d3ĩ.nwa.'sĩ] R. [a.'ke.li.kI.'põj.ka.nu.'d31̃.na.'sĩ]

Os casos em (33)-(35) mostram uma aplicação ou bloqueio das regras por parte de R. coerente como uso adulto. Em (33), a regra não é aplicada porque 'esse' porta o acento entonacional. Como visto na seção 2, alguns falantes violam essa proibição nos casos em que a primeira vogal tem o traço [ + alto]. No entanto, em (33) é a segunda vogal quem porta este traço. Assim, a regra é totalmente bloqueada na fala adulta. Em (34), o contexto segmental e de proeminências bloqueia a aplicação de qualquer regra; isto é, degeminação não pode ser aplicada porque as vogais são diferentes; no caso de elisão, a regra é bloqueada porque a primeira vogal do contexto é acentuada; finalmente, a aplicação de ditongação também é bloqueada porque nenhuma das vogais tem o traço [+ alto]. Em (35), R. aplica a ditongação, num contexto em que adultos poderiam tanto ditongar quanto aplicar elisão. Todos estes dados mostram que R. faz um uso mais próximo da fala adulta no que concerne a aplicação das regras dados os contextos corretos. Mas ainda ocorrem algumas aplicações indevidas das regras. Em (37), embora o contexto permita ditongação ou elisão ('canudinho assim', em que a primeira vogal tem o traço [ + anterior] e é fraca), adultos preferem ditongação. No entanto, R. aplica elisão, e apaga a primeira vogal, novamente mantendo a vogal /a/, como nas fases anteriores.

Cumpre chamar a atenção que em todos os casos ((33)-(37)), a seqüência de proeminências das produções de R. é otimizada ritmicamente. Independentemente de $\mathrm{R}$. usar uma regra diferente do adulto, a seqüência de sílabas resultante é forte-fraca-forte ('chama esse' ['Jã.ma'e],'so arroz' ['so.a.'xoz], 'canudinho assim' [nu'dzi.na'si]). Em (35), a seqüência inicial 
era forte-fraca-fraca-fraca-forte ('tudo a comida'). Com a aplicação da regra de ditongação, a seqüência passa a forte-fraca-fraca-forte (['tu.dwa.ko'mi]), a mais eurrítmica possível, dado o contexto.

Finalmente, em (36), há contexto para ditongação, e a regra é normalmente aplicada pelos adultos. No entanto, a aplicação da regra cria um encontro acentual ('parece uma' [pa're.'sju.ma]), o que gera uma seqüência menos eurrítmica do que a que R. gera, ao não aplicar nenhuma regra. Isto mostra que, nesta fase, as regras são mais estáveis e usadas para propósitos rítmicos.

\section{d) Fase IV:}

Neste momento, a aplicação das regras é como a fala adulta. Não foi encontrado nenhum caso de super-aplicação de regras de sândi externo.

$3 ; 6.23$ anos:

38) é porque eu vou limpar a boca. adulto ['E.por.'kew.'vo.lî.'pa.ra.'bo.ka]

R. ['e.por.'kew.'vo.lĩ.'pa.a'bo.ka]

39) tem um machucadinho aqui que passa sabão. adulto ['tẽ.ũ.ma.Ju.ka.'di.jwa.'ki.ke.'pa.sa.sa.'bãw]

R. ['tẽ.ũ.ma.Ju.ka.'di.nwa.'ki.ke.'pa.sa.sa.'bãw]

40) você esqueceu de me dar remédio. adulto ['sejs.ke.'sew.de.me.da.xe.'me.dju]

R. ['sejs.ke.'sew.de.me.da.xe.'me.dju]

41) não pode lavar esse. ['nãw.'po.dzI.la.'va.'re.sı] ['nãw.'po.dzI.la.'va.'e.sı]

42) não pode lavar esse pé adulto ['nãw.'po.d3ı.la.'va.'re.sı.'pe] ['nãw.'po.d3I.la.'vaj.sı.'pe]

R. ['nãw.'po.dzi.la.'vaj.sı.'pe]

Todos os exemplos acima mostram que R. aplica as mesmas regras que os adultos. Em (38), a aplicação da ditongação diminui uma sílaba na seqüência de encontro acentual ([por'ke.'ew.'vow]); em (39)-(40), a ditongação elimina uma sílaba na seqüência de lapso ([mafuka'di.nu.a.'ki] e [vo.'se.es.ke.'sew]). Os dados mais interessantes são o par (41)-(42), que claramente mostra que o sândi é bloqueado quando a segunda sílaba recebe acento entoacional (cf. (41)), mas que a regra pode ocorrer se a sílaba carrega apenas acento de palavra (cf. (42)). 


\section{Discussão dos dados de aquisição}

Os resultados apresentados em 3 levantam algumas questões sobre o desenvolvimento do sistema prosódico. Scarpa (1997) analisou a fala de duas crianças, entre 2 e 2;6 anos, adquirindo o português brasileiro, e argumenta que as crianças usam a degeminação e a elisão por volta dos dois anos de idade. Embora a aplicação das regras seja variável e instável, a autora aponta que as crianças nunca aplicam a regra de sândi se uma das sílabas envolvidas no contexto carrega o acento frasal (acento entonacional). Ela também argumenta que a instabilidade na aplicação das regras é evidência de que, embora as crianças já tenham domínio do acento frasal e portanto, no nível entoacional -, elas ainda estão adquirindo os níveis mais baixos da hierarquia prosódica - o pé. Finalmente, Scarpa argumenta que, durante o processo de aquisição "Metrical "mistakes" in this situation point both to over-and to underapplication of sandhi in the data analysed." (1997).

Os dados apresentados neste trabalho estão de cordo com a principal afirmação de Scarpa, isto é, que o acento entoacional bloqueia a aplicação de regras de sândi externo mesmo nos enunciados mais iniciais. Quanto à questão da variação na aplicação das regras e dos erros métricos, nossos dados apontam para uma explicação do que sejam.

Inicialmente, apresentamos a discussão sobre o bloqueio de regras pelo acento entoacional a partir de nossos dados e, num segundo momento, discutimos a variação/erros infantis.

\subsection{Dominio do nível entonacional}

Pudemos observar, nas fases discutidas aqui, que a única exigência das regras de sândi que $\mathrm{R}$. sempre obedeceu foi a de não aplicar a regra se a segunda sílaba carregasse acento entonacional. De acordo com Scarpa (1997), as crianças adquirindo português dominam o nível entoacional muito cedo, enquando ainda estão adquirindo os níveis ais baixos da hierarquia prosódica (pé) e que esta obediência é uma evidência de que as crianças não iniciam o processo de aquisição da hierarquia prosódica a partir dos níveis mais baixos e vão subindo (bottom-up process), como é argumentado na literatura sobre o assunto (cf. Demuth (1995) para o inglês, entre outros). Os estudos sobre holandês e ingles defendem que as crianças 
começam com a sílaba e seguem para o pé, e depois para a palavra, como exemplificado pela proposta de Demuth:

43) estágio I: sílaba CV

estágio II: palavra mínima igual a um pé binário

estágio III: palavra mínima maior do que o pé binário

estágio IV: palavra fonológica (igual a palavra adulta)

No entanto, se as crianças começam trabalhando a partir dos níveis mais baixos para os mais altos, a questão que se coloca é: por que R., desde as primeiras produções em que aplica sândi, sempre obedece à restrição de bloqueio quando há proeminência acentual na segunda sílaba? Os dados discutidos aqui mostram que a obedência a esta exigência ocorre desde $1 ; 8$, quando a maioria dos estudos em aquisição da linguagem estão discutindo sobre a existência de uma tendência trocaica inata nas produções infantis (cf. Allen \& Hawkins 1980, Gerken 1994, Rapp 1994, Archibald 1995, Santos 2001, Baia 2005, entre outros). Se argumentamos que há ou que não há - uma tendência trocaica na produção infantil neste momento, estamos assumindo que as crianças estão lidando com o constituinte prosódico 'pé'. Se as crianças “sobem” na hierarquia prosódica, R. não teria a proeminência entoacional com que lidar e poderia violá-la na aplicação das regras de sândi. A questão para uma proposta "bottom-up" seria, então, quais as evidências de que as crianças não estão lidando com outros níveis prosódicos (mais altos). Até onde sabemos, não há estudos sobre esta questão.

Uma outra possibilidade de interpretação dos dados é inverter a aquisição do sistema prosódico: as crianças começariam com os níveis prosódicos mais altos e "desceriam" na hierarquia. Esta é a proposta de Scarpa (1997, 2001), conhecida como "top-down". De acordo com Scarpa (2001), uma vez que a hierarquia prosódica pode ser preenchida por apenas uma sílaba (cf. (45)), não há nada que impeça que que o arcabouço prosódico das primeiras "palavras" sejam arcabouços de níveis prosódicos mais altos (cf. (44)):

44) (x) sentença

(x) frase entonacional

(x) frase fonológica

(x) palavra fonológica

(x) pé

(x) sílaba

não 
Usando um dos exemplos discutidos em 3.2, podemos observar que, embora a combinação lexical seja evidência do domínio da frase fonológica (combinação entre um verbo e seu complemento - cf. Nespor \& Vogel 1984), o bloqueio da ditongação pela proeminência entoacional é evidência de que esta sentença também foi mapeada pelo domínio da frase entoacional (cf. (16), repetido aqui): ${ }^{4}$

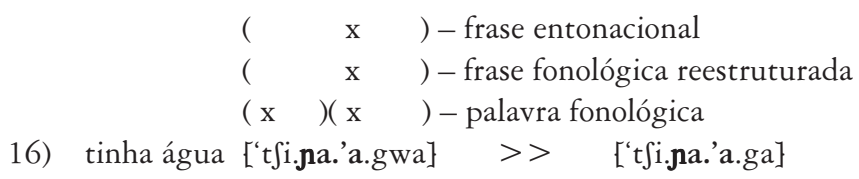

Assim, é teoricamente possível que as crianças estejam lidando com o nível entonacional. Os argumentos abaixo, que discutem a sensibilidade à categorias prosódicas em um período bem inicial ( 9 meses de idade), apontam que, mais do que possível, esses dados apóiam a proposta de que a aquisição da hierarquia prosódica começa a partir dos níveis mais altos.

Scarpa (2001) argumenta que o bloqueio das regras de sândi pelo acento pressupõe estabilidade da proeminência frasal. Em outras palavras, R., em nenhum caso, aplica uma regra de sândi quando há uma proeminência acentual entoacional envolvida. Isto mostra que ela não está somente lidando com o nível entoacional mas que já domina ao menos alguma de suas características. Uma vez que as regras de aplicação das regras de sândi externo exigem a computação da proeminência do nível entonacional, o fato de que esta exigência é obedecida desde o início do processo de aquisição aponta que a criança já trabalha com o nível entoacional ou tem, ao menos, alguma familiaridade com os níveis mais altos da hierarquia prosódica. Se a aquisição prosódica ocorresse de maneira "bottom-up", nós incorretamente esperaríamos que em algum momento (ao menos no começo do processo), as regras de sândi não levassem em conta o acento entonacional.

Outras evidências podem ser apresentadas para a proposta "top-down" de Scarpa. Por exemplo, no que respeita à produção, Santos (2001, 2005a) mostra que, no começo do processo de aquisição do acento primário em português brasileiro, as crianças (incluindo R.), usam o acento entoacional como acento primário; Gebara (1984) aponta que o desenvolvimento do

4 Apresentamos apenas os níveis relevantes para a discussão. 
sistema entoacional começa por volta dos 11 meses; e Freitas (1997) aponta que as crianças, durante o estágio do balbucio, desenvolvem um sistema entoacional vazio de informações fonológicas segmentais. Estudos sobre percepção também mostram que crianças, aos 9 meses de idade, já são sensíveis a categorias prosódicas (cf. Gerken, Jusczyk \& Mandel 1994, entre outros).

\subsection{Variação e erros nas produçôes infantis}

De acordo com Scarpa, a produção das crianças, entre 2 e 2;6 anos, apresenta muita variação e alguns "erros" de super- e sub-aplicação das regras. Estendendo o período de análise e mambas as direções - iniciando aos $1 ; 4$ e terminando aos 3;6 -, acreditamos ter observado o porque das variações e erros. Segundo Scarpa, as crianças super-aplicam e sub-aplicam as regras de sândi externo. A partir dos dados apresentados em 3.2, propomos que os erros das crianças não sejam só de sub-aplicação e super-aplicação de regras, mas de uso diferente do uso adulto. Nossos argumentos, para tal proposta, são os que se seguem: em primeiro lugar, não podemos falar de sub-aplicação das regras uma vez que as regras de sândi são opcionais em português brasileiro; isto é, dado o contexto, não é necessário, mas possível que as regras se apliquem (cf. Tenani 2002). Assim, não podemos exigir a aplicação das regras pelas crianças se nem os adultos aplicam essas regras o tempo todo (cf., por exemplo, as possibilidades de produção por adultos de (42)).

No que se refere à super-aplicação das regras, observamos que elas ocorrem em um momento específico (fase III) na fala de R. Assim, a superaplicação das regras tem um motivação específica para ocorrer. Essa motivação já foi apontada por Scarpa (2001): a implementação rítmica.

Mas R. incorre em outros "erros" que não podem ser classificados como super-aplicação de regras. Um tipo de "erro" é a aplicação de regras diferentes das que o adulto falante de português faria. É assim que ela usa elisão em contextos que o adulto usaria ditongação, por exemplo. Outro tipo de "erro" é a violação de outros aspectos, que não o bloqueio pelo acento entonacional, das regras de sândi. Normalmente estas violações referem-se a aspectos segmentais dessas regras, como por exemplo, a manutenção da vogal /a/ em casos de elisão, mesmo quando ocupando a segunda 
sílaba do contexto (para uma discussão sobre os tipos de desvios das regras de sândi pelas criançs, cf. Santos 2005b).

Levando em conta a variação, instabilidade e otimização rítmica dos enunciados, identificamos 4 momentos nas produções de R.:

a) I: produções de uma palavra; não há contexto para aplicação das regras;

b) II: aplicação instável das regras (uso de regras diferentes das dos adultos, violação de exigências segmentais das regras); regras não são usadas para otimização rítmica; obediência ao acento entonacional;

c) III: aplicação instável das regras (uso de regras diferentes das dos adultos, violação de exigências segmentais das regras); obediência ao acento entonacional; regras utilizadas para otimização rítmica;

d) IV: aplicação conforme a fala adulta.

\section{Considerações Finais}

O objetivo deste artigo era analisar a aquisição das regras de sândi externo por crianças adquirindo o português brasileiro, e responder a duas questões: a) quando e como as regras de sândi externo aparecem na produção de R. b) qual a relação destas regras com o desenvolvimento do sistema prosódico. Ao final da análise dos dados, podemos dizer que as regras de sândi externo aparecem tão logo R. começa a combinar duas palavras em um mesmo enunciado. Inicialmente elas são instáveis no que diz respeito tanto a aplicação das regras como a escolha da regra a ser aplicada. Podemos também afirmar que o uso das regras para implementação rítmica não ocorre no início do processo de aquisição. Finalmente, as regras adquirem as características adultas e R. passa a usá-las como os adultos por volta dos 3;6. Quanto à relação das regras com o desenvolvimento do sistema prosódico, nossa análise corrobora a proposta de Scarpa de que as regras são evidência de que as crianças dominam os níveis mais altos da hierarquia prosódica antes dos níveis mais baixos. 
Recebido em julho de 2005

Aprovado em abril de 2007

E-mail: raquelss@usp.br

\section{REFERENCES}

Allen, George \& Sarah Hawnins. 1980. Phonological rhythm: definition and development. In G. Yeni-Konishian; Jeannette Kavanagh \& Cristina Ferguson, Eds. Child Phonology - production vol. 1:227-256 New York: New York Academic Press

Archibald, John 1995. The acquisition of stress. In: John Archibald, Ed. Phonological Acquisition and Phonological Theory 81-109 Hillsdale, N. J.: Lauren Erlbaum Associates.

BAIA, Maria de Fátima de Almeida. 2005. Relatório de iniciação científica para FAPESP (processo 03/13139-5). Universidade de São Paulo

Bisol, Leda. 1989. O ditongo da perspectiva da fonologia atual. D.E.L.T.A. vol. $5 \mathrm{n}^{\mathrm{o}} 2: 185-224$.

. 1992(a). Sândi vocálico externo. In: Rodolfo ILARI, Ed. Gramática do Português Falado II. Campinas: Unicamp

. 1992(b). Sândi vocálico externo: degeminação e elisão. Cadernos de Estudos Linguísticos. n. 23:83-101.

. 1996. Sândi externo: o processo e a variação. In: Rodolfo ILARI, Ed. Gramática do Português Falado IV. Campinas: Unicamp . 2003. Sandhi in Brazilian Portuguese. Probus v.15, n.2: 177-200.

Brescancini, Cláudia Regina. 2005. A elisão da vogal média no sul do Brasil. In Letras de Hoje, v. 40, n. 3:39-56

Demuth, Katherine. 1995. Markedness and the development of prosodic structure. In: Jill Beckman (ed.). Proceedings of the North East Linguistic Society vol. 25:13-25. Amherst, MA: GLSA.

Demuth, Katherine \& E J Fee. 1996. Minimal prosodic words in early phonological development. Ms. Brown University \& Dalhousie University.

Fikkert, Paula. 1994. On the Acquisition of Prosodic Structure. Holland: Holland Institute of Generative Linguistics

Freitas, Maria João. 1997. Aquisição da estrutura silábica no Português Europeu Tese de doutorado, Universidade de Lisboa.

GeBARA, Ester Mirian Scarpa. 1984. The development of Intonation and Dialogue Processes in two Brazilian Children. Tese de doutorado. Londres 
Gerken, Lou Ann. 1994. A metrical Template account of children's weak syllable omissions from multisyllabic words. Journal of Child Language vol.21: 565-584.

Gerken, Lou Ann; Peter Jusczyk \& D R Mandel. 1994. When prosody fails to cue syntactic structure: nine-month-olds' sensitivity to phonological vs. syntactic phrases. Cognition n.51: 237-265.

Komatsu, Mariana Oshida. 2003. Relatório final de iniciação científica para CNPq/PIBIC. Universidade de São Paulo

Lemos, Cláudia Thereza Guimarães. 1995. Aquisição da Linguagem. Relatório para FAPESP 1976/1384 FAPESP 1985/3325-6 CNPq 404672-88.4 FAEP 190/90

Matthei, Edward 1989. Crossing boundaries: more evidence for phonological constraints on early multi-word utterances. Journal of child language. vol. 16: 41-54.

Mezzomo, Carolina \& Gabriela Menezes. 2001. Comparação entre a aquisição da estrutura silábica no português brasileiro e no português europeu. Letras de Hoje vol. 36 n. 125: 691-698.

Newton, Caroline \& Bill Wells. 2002. Between-word junctures in early multi-word speech. Journal of Child Language vol. 29: 275-299.

Nogueira, Milca Veloso. 2006. Sândi vocálico em português brasileiro: uma nova discussão sobre a regra de elisão. Comunicação apresentada no 540. Seminário do GEL.

. 2007. As regras de sândi vocálico em São Paulo. Dissertação de Mestrado. Universidade de São Paulo

RAPP, Carola. 1994. A elisão das sílabas fracas nos estágios iniciais da aquisiz̧ão da fonologia do português. Dissertação de mestrado. Universidade Federal da Bahia.

SANTOS, Raquel Santana. 1998. A aquisição da estrutura silábica. Letras de Hoje n. 112:91-98. . 2001. A aquisição do acento de palavra no Português Brasileiro. Tese de doutorado. Universidade de Campinas . 2005(a). Strategies for the acquisition of Word Stress in Brazilian Portuguese. In: Marina Tzarovska \& Jeroen van DE Wejer, Eds. Leiden Working Papers in Linguistics n.2.1:71-91. . 2005(b). Some issues in the acquisition of external sandhi in Brazilian Portuguese. Ms. Universidade de São Paulo. prep. Revisitando a regra de elisão. 
SCARPA, Ester Mirian. 1997. Learning external sandhi. Evidence for a topdown hypothesis of prosodic acquisition. In: Antonella SORACE, Caroline Heycock \& Richard Shillcock, Eds. Proceedings of GALA'1997 Conference on Language Acquisition: knowledge representation and processing. . 2001. O recurso a níveis prosódicos superiores na aquisição e na afasia. Palavra n.6:48-62.

Stemberger, Joseph Paul. 1989. Speech errors in early child language production. Journal of Memory and Language vol. 28 n.2:164-188.

Tenani, Luciani Ester. 2002. Domínios prosódicos no Português do Brasil: implicações para a prosódia e para a aplicação de processos fonológicos. Tese de doutorado. Universidade de Campinas.

Veloso, Brenda. 2003. O Sândi vocálico externo e os monomorfemas em três variedades do português. Dissertação de Mestrado. Universidade de Campinas. 